\title{
ENRAIZAMENTO IN VITRO E ACLIMATIZAÇÃO DE GENÓTIPOS DE JENIPAPEIRO (Genipa americana L.) ${ }^{\mathbf{1}}$
}

\author{
MOEMA ANGÉLICACHAVES DA ROCHA², MARIA ANGÉLICA PEREIRADE CARVALHO COSTA², \\ SIMONE ALVES SILVA ${ }^{3}$, CARLOS ALBERTO DA SILVALEDO ${ }^{4}$, \\ MARIA JOSIRENE SOUZA MOREIRA ${ }^{5}$, LUCIMÁRIO PEREIRA BASTOS ${ }^{6}$
}

RESUMO - A rizogênese é considerada uma fase crítica na regeneração de plantas in vitro, pois determina a sobrevivência das mesmas durante a aclimatização. Dentre os fatores determinantes na indução e na formação de raízes in vitro, destacam-se o genótipo e as auxinas. O objetivo deste trabalho foi avaliar o efeito de diferentes concentrações do ácido 4-indol-3-butírico (AIB) no enraizamento in vitro de dois genótipos de jenipapeiro (Genipa americana L.) JRB59 e JRB69, bem como no processo de aclimatização das microplantas utilizando diferentes substratos. Para o enraizamento, brotos com aproximadamente $2,0 \mathrm{~cm}$ de comprimento, provenientes do cultivo em meio de cultura com 6-benzilaminopurina (BAP), nas concentrações de 2,22; 8,87; 17,74 e 26,76 $\mu \mathrm{M}$ mais a testemunha com ausência do BAP, foram introduzidos em meio de cultura MS, suplementados com 4,9; 9,8 e 14,7 $\mu \mathrm{M}$ de AIB mais a testemunha com ausência de AIB. Quanto ao processo de aclimatização, utilizaram-se como substratos areia lavada, Plantmax ${ }^{\circledR} \mathrm{HT}_{\text {e Ecoterra }}{ }^{\circledR}$. As variáveis analisadas foram: porcentagem de enraizamento, número de raízes adventícias, comprimento da maior raiz, porcentagem de sobrevivência e altura das plantas na fase de aclimatização. Os resultados mostraram que a auxina AIB, na concentração de $9,8 \mu \mathrm{M}$, foi mais eficiente para indução do enraizamento, com percentual acima de 70\%, para o genótipo JRB69, e 43,3\% para o genótipo JRB59. O substrato Ecoterra ${ }^{\circledR}$ influenciou significativamente na qualidade do sistema radicial e qualidade da parte aérea.

Termos para indexação: rizogênese, auxinas, cultivo in vitro.

\section{IN VITRO ROOTING AND ACCLIMATATION OF GENOTYPES OF JENIPAPEIRO}

\section{(Genipa americana L.)}

ABSTRACT- The rhizogenesis is considered a critical stage, since it determines the plant survival during the acclimatization. Among the determinative factors in the induction and the formation of in vitro roots, is distinguished the genotype and the auxin. The objective of the work was to evaluate the effect of different concentrations of acid 4-indol-3-butírico (IBA) in the in vitro rooting in genotype of Genipa americana L; as well as the process of acclimatization of the plant using different substrate. For the in vitro rooting stage, shoots of $2.0 \mathrm{~cm}$ long, proceeding from the culture medium with 6-benzilaminopurina (BAP) in concentrations of 2,22; 8,$87 ; 17,74$ and $26,76 \mu \mathrm{M}$ plus the witness with absence of the BAP, were inoculated in medium MS supplemented with IBA (4.9; $9.8 \mathrm{e}$ $14.7 \mu \mathrm{M})$ plus the witness with IBA absence. To the acclimatization process it was used as supporting material washed sand, Plantmax ${ }^{\circledR}$ HT and Ecoterra ${ }^{\circledR}$. The variables analyzed were: percentage of rooting, number of adventitious roots, and length of the largest root, percentage of survival and height of the plant in the acclimatization phase. The results showed that IBA at $9.8 \mu \mathrm{M}$ induced greater rooting percentage. The substrate Ecoterra ${ }^{\circledR}$ influenced significantly in the quality of root system and quality of the aerial part.

Index terms: rhizogenesis, auxin, tissues culture.

\section{INTRODUÇÃO}

A obtenção de plantas in vitro com um sistema radicial bem desenvolvido é de grande importância para a sua sobrevivência e crescimento, principalmente quando da aclimatização e transplantio para o campo.

A capacidade dos tecidos para formação de raízes depende de vários fatores endógenos e/ou exógenos e suas interações. O papel das auxinas na indução e no desenvolvimento de raízes tem sido bastante estudado, sendo as principais auxinas utilizadas: AIB (4-indol-3-butírico), ANA(ácido naftaleno-acético) e AIA (ácido indol-3-acético) (Lopes et al., 2001; Machado et al., 2005), em concentrações que variam conforme a espécie e/ou cultivar. As concentrações mais freqüentes estão na faixa de 0,5 a 5,0 $\mu \mathrm{M}$ (Gattapaglia \& Machado, 1998).

A fase de aclimatização das plantas oriundas do cultivo in vitro é bastante delicada. Essa fase é apontada como uma das mais críticas do processo de regeneração, em que ocorre a maioria das perdas. Durante esse estádio, as microplantas são expostas

${ }^{1}$ (Trabalho 165-07). Recebido em: 04-07-2007. Aceito para publicação em: 24-04-2008. Parte da dissertação apresentada ao Mestrado em Ciências Agrárias da Universidade Federal do Recôncavo da Bahia (UFRB) pelo primeiro autor, para obtenção do título de Mestre em Ciências Agrárias.

2Doutoranda em Ciências Agrárias pela UFRB, moemachaves@yahoo.com.br. Cruz das Almas-BA, CEP. 44380-000.

${ }^{3}$ Doutora em Fitotecnia, Prof ${ }^{a}$ da UFRB, mapcosta@ufba.br, sas@ufba.br. Cruz das Almas-BA, CEP.44380-000.

${ }^{4}$ Doutor, Pesquisador da EMBRAPA Mandioca e Fruticultura Tropical, ledo@cnpmf.embrapa.br. Cruz das Almas-BA, CEP.44380-000.

${ }_{5}^{5}$ Mestranda em Ciências Agrárias da UFRB, mjmoreira@yahoo.com.br. Cruz das Almas-BA, CEP.44380-000.

${ }^{6}$ Engenheiro Agrônomo da EBDA, agronero@yahoo.com.br Cruz das Almas-BA, CEP.44380-000. 
a mudanças súbitas nas condições ambientais, devido à transferência de um ambiente in vitro para o meio externo. As microplantas irão desenvolver mecanismos de controle de transpiração e condutância estomática (Díaz-Perez et al., 1995), ativar os mecanismos de controle de perda de água pelas células (Sutter, 1988) e aumentar a taxa fotossintética em condições de atmosfera mais rica em $\mathrm{CO}_{2}$ (Vantelgen et al., 1992).

Um fator de elevada importância na aclimatização, além do controle de umidade e condições de cultivo, é o tipo de substrato. Segundo Calvete et al. (2000), as propriedades do substrato podem facilitar ou impedir o desenvolvimento das plantas.

De modo geral, são poucos os trabalhos de cultivo in vitro que relatam as dificuldades e soluções para o processo de aclimatização. Possivelmente, a familiarização com a cultura e as condições de trabalho disponíveis são fatores determinantes para o sucesso dessa fase.

O objetivo deste trabalho foi avaliar o efeito residual do 6-benzilaminopurina (BAP) à influência do 4-indol-3-butírico (AIB) no enraizamento in vitro de brotações adventícias em dois genótipos de jenipapeiro (Genipa americana L.) e posterior aclimatização, utilizando diferentes tipos de substratos.

\section{MATERIAL E MÉTODOS}

O trabalho foi desenvolvido no Laboratório de Cultura de Tecidos Vegetal do Departamento de Fitotecnia, no Centro de Ciências Agrárias, Ambientais e Biológicas da Universidade Federal do Recôncavo da Bahia (UFRB).

Obtenção das brotações adventícias

Como fonte de explantes, foram utilizadas sementes de jenipapeiro de frutos maduros coletados de plantas situadas em duas localidades do Recôncavo Baiano, denominadas de JRB59, localizada no município de Cruz das Almas - BA, e JRB69, localizada no povoado de Outeiro Redondo, na região de Maragojipe-BA.

Inicialmente, as sementes foram lavadas em água corrente e, posteriormente, em câmara de fluxo laminar, foram desinfestadas com imersão em álcool a $70 \%$ por 1 minuto, seguido de solução de hipoclorito de sódio (a $2,5 \%$ de cloro ativo), diluído na proporção 2:1(v:v), com duas gotas de detergente comercial, durante 20 minutos, e lavadas cinco vezes em água destilada autoclavada. Em seguida, foram inoculadas cinco sementes por frasco de vidro $(100 \times 70 \mathrm{~mm}) \mathrm{em}$ meio de cultura MS (Murashige \& Skoog, 1962), acrescido com 30 g.L. ${ }^{-1}$ de sacarose e 2 g.L.$^{-1}$ de Phytagel $^{\circledR}$, com pH ajustado para 5,7 $\pm 0,1$, antes da autoclavagem, à temperatura de $121^{\circ} \mathrm{C}$, por 20 minutos e $1,3 \mathrm{Kgf} / \mathrm{cm}^{2}$ de pressão. O cultivo foi realizado sob condições de fotoperíodo de 16 horas, temperatura de $25 \pm 2^{\circ} \mathrm{C}$ e densidade de fluxo de fótons de 22 $\mu \mathrm{E} \cdot \mathrm{m}^{-2} \cdot \mathrm{s}^{1}$. Após 65 dias de semeadura, quando as sementes emitiram a radícula e a parte aérea, foram retirados segmentos de hipocótilo e introduzidos em tubos de ensaio ( $25 \times 150 \mathrm{~mm})$ contendo o meio de cultura MS, suplementado com 30 g.L. ${ }^{-1}$ de sacarose, 2 g.L.$^{-1}$ de Phytagel $^{\circledR}$ e BAP (6-benzilaminopurina), nas concentrações: 2,$22 ; 8,87 ; 17,74$ e $26,76 \mu \mathrm{M}$ mais a testemunha com ausência do BAP.

\section{Enraizamento in vitro das brotações adventícias}

Brotações adventícias, com aproximadamente $2,0 \mathrm{~cm}$ de comprimento, foram cultivadas em tubos de ensaio ( $25 \times 150 \mathrm{~mm})$ contendo meio de cultura MS, suplementado com AIB (ácido 4indol-3-butírico), nas concentrações de 4,9; 9,8 e 14,7 $\mu \mathrm{M}$ mais a testemunha com ausência do AIB. Foram avaliados os percentuais de enraizamento, número de raízes adventícias e comprimento da maior raiz aos 30 e 60 dias após a incubação.

\section{Aclimatização}

Utilizaram-se plantas enraizadas in vitro, após 75 dias de incubação em meio de cultura contendo AIB, foram retiradas dos tubos de ensaio e tiveram suas raízes lavadas em água corrente para a remoção do excesso de meio de cultura. Em seguida, foram transferidas para copos plásticos de $200 \mathrm{~mL}$, perfurados, para drenagem do excesso de água, contendo três substratos distintos: areia lavada, marca comercial Plantmax ${ }^{\circledR} \mathrm{HT}$ e substrato orgânico marca comercial Ecoterra ${ }^{\circledR}$. Ao final de 30 dias, foram avaliadas a porcentagem de plantas sobreviventes, qualidade da parte aérea, mensurada pelo comprimento da parte aérea $(\mathrm{cm})$, coloração das folhas, emissão de folhas novas e expansão das existentes, e qualidade do sistema radicial. Para este parâmetro cinco plantas foram retiradas do substrato e por observação visual avaliadas quanto ao desenvolvimento e ramificação do sistema.

As plantas permaneceram durante cinco dias em bandeja coberta com plástico transparente, na sala de crescimento, com temperatura de $27 \pm 1^{\circ} \mathrm{C}$; posteriormente, foram transferidas para viveiro telado, à temperatura ambiente, onde permaneceram por mais 10 dias. Após este período, retirou-se totalmente a cobertura plástica onde as plantas permaneceram por 15 dias.

\section{Análise estatística}

Para o enraizamento, foi realizada análise de variância considerando o delineamento inteiramente casualizado, no esquema fatorial $4 \times 5 \times 2$, sendo quatro concentrações de AIB, 5 concentrações de BAP e 2 genótipos, com 6 repetições e uma brotação adventícia por unidade experimental. A variável número médio de raízes adventícias foi transformada para raiz $(x+0,5)$, e o comprimento médio da maior raiz, transformado para log $(x+$ 10), visando ao atendimento das pressuposições da análise de variância. As análises estatísticas foram realizadas utilizando o programa estatístico "SAS - Statistical Analysis System" (SAS Institute Inc., 2000). Para a aclimatização, o delineamento experimental foi inteiramente casualizado, com arranjo fatorial $2 \mathrm{x}$ 3 (2 genótipos e 3 tipos de substratos), com 10 repetições por tratamento e uma planta por unidade experimental. Para a comparação de médias, foi empregado o teste de Tukey, a 5\% de probabilidade, utilizando o programa estatístico SISVAR (Ferreira, 2000).

\section{RESULTADOS E DISCUSSÃO}

A Tabela 1 demonstra o resumo da análise de variância para o número de raízes adventícias (NRA) e comprimento da 
maior raiz (CMR). Houve efeito significativo $(\mathrm{P} \leq 0,01)$ para AIB, genótipo, AIB x genótipo e BAP x genótipo, para as duas variáveis analisadas. Não houve efeito significativo para a interação tripla AIB x BAP x genótipo, assim como para o regulador BAP isoladamente. A interação AIB x BAP foi significativa apenas para a variável número médio de raízes adventícias.

A técnica de propagação in vitro baseia-se, principalmente, no cultivo de brotos em meio enriquecido com citocininas que induzem a multiplicação dos mesmos. Estes então são transferidos a meios de cultura, geralmente contendo auxinas, para que possam enraizar. No entanto, existem espécies e cultivares com pouca habilidade para o enraizamento in vitro, e o efeito dos reguladores utilizados na fase de multiplicação pode interferir na rizogênese. Este comportamento foi verificado para o genótipo JRB59, que apresentou menor número e comprimento médio de raízes, à medida que aumentou a concentração de BAP no meio de multiplicação. Quanto ao genótipo JRB69, estas variáveis não foram influenciadas pelo meio de multiplicação (Tabela 2)

Para a maioria dos tratamentos, ocorreu formação de calos na base das brotações (Fig. 1), que variaram conforme o aspecto friável e compacto. De acordo com Welander \& Snygg (1987), a formação de calos está muito ligada às concentrações e tipo de auxina no meio de cultura. Erig et al. (2004) afirmam que a formação de calo na zona de enraizamento é indesejável, pois ela pode afetar a qualidade das raízes, principalmente no que se refere à conexão vascular com a planta. Contudo, os resultados obtidos neste trabalho sugerem que a rizogênese das brotações não foi prejudicada com a ocorrência de calos.

A ausência de AIB no meio de enraizamento não proporcionou a formação de raízes, independentemente das concentrações de BAP utilizadas no meio de indução; esse fato sugere que, para a espécie em estudo, o AIB foi efetivo na promoção do enraizamento. $\mathrm{O}$ maior percentual de brotos enraizados foi de $70 \%$ e $43 \%$ para os genótipos JRB69 e JRB59, respectivamente, demonstrando o maior potencial genético do genótipo JRB69 (Tabela 3). Portanto, a resposta dos explantes em um sistema de cultura de tecidos depende do material vegetal. Resultados semelhantes foram relatados por Sobrosa \& Corder (2003) quanto às diferentes respostas dos genótipos in vitro para produção de gemas e raízes adventícias em Eucalyptus grandis HILL ex Maiden, e Santana (2003) no estudo do controle da morfogênese em Anonnaceae. Por outro lado, a concentração de 9,8 $\mu \mathrm{M}$ de AIB apresentou maior percentagem de enraizamento, independentemente do genótipo quando comparado com as demais concentrações (Tabela 3). Resultados semelhantes foram relatados por Erig \& Schuch (2004). Avaliando a influência do AIB no desenvolvimento in vitro de plantas de marmeleiro cv. MC, observaram que a concentração de $10 \mu \mathrm{M}$ do AIB promoveu maior porcentagem de enraizamento.

Concentrações acima de 9,8 $\mu \mathrm{M}$ de AIB diminuíram o número e o comprimento das raízes adventícias, bem como contribuíram para uma menor porcentagem de brotos com raízes adventícias (Figuras 2 e 3; Tabela 4). Radmann et al. (2002), estudando concentrações que variaram de 0,5 a $100 \mu \mathrm{M}$ de AIB, verificaram redução na porcentagem de enraizamento do porta- enxerto de macieira 'M9' nas concentrações mais altas.

O AIB é um regulador de crescimento comprovadamente responsável pela indução de enraizamento, conforme considerações de Gratapaglia \& Machado (1998), sendo que, na sua ausência, dependendo da espécie, a formação de raízes é nula ou restringe-se a alguns brotos (Willians et al., 1985). Tricoli et al. (1985), Magalhães Jr \& Peters (1991) observaram que a auxina, embora responsável pela indução de enraizamento, inibe o crescimento ou alongamento das raízes em altas concentrações.

Trinta dias após o início da aclimatização, obtiveram-se $70 \%$ e 30\% de sobrevivência para os genótipos JRB69 e JRB59, respectivamente (Tabela 5). A redução no número de plantas sobreviventes ocorreu após as plantas terem sido transferidas da sala de crescimento, aliado à retirada da cobertura plástica, a qual simulava uma câmara úmida. Este fato se deve, em grande parte, à mudança das condições ambientais nas quais as plantas foram submetidas. Resultados semelhantes foram relatados por Erig \& Schuch (2004) em estudos com marmeleiro cv. MC.

A perda excessiva de água pelas mudas produzidas in vitro é apontada como um dos principais fatores envolvidos na aclimatização, tendo em vista que a remoção das mudas das condições in vitro provoca um estresse crítico, sendo então necessário manter a umidade alta e a temperatura amena, pelo menos no início do processo (Souza et al., 2006).

As plantas que receberam o substrato Plantmax ${ }^{\circledR}$ HT como tratamento não sobreviveram à aclimatização, apresentando contaminação por fungo no colo e apodrecimento do sistema radicial (Tabela 6). Possivelmente, este fato ocorreu devido a um manejo inadequado, levando a uma drenagem ineficiente, favorecendo, portanto, o desenvolvimento de fungos. Segundo Bebendo (1995), os patógenos causadores de podridões de raiz e colo podem atacar plantas desde seu estádio inicial de desenvolvimento até o estádio adulto. De modo geral, plantas jovens oferecem menor resistência ao ataque dos patógenos e podem morrer rapidamente.

Os substratos Ecoterra ${ }^{\circledR}$ e areia lavada foram eficientes no sistema de aclimatização. Independentemente das suas características físicas, químicas e biológicas, entretanto, estes fatores foram preponderantes para o desenvolvimento das plantas (Tabela 6). O teor de matéria orgânica $\left(204 \mathrm{~g} \cdot \mathrm{dm}^{-3}\right)$, aliado à concentração de $\mathrm{P}\left(970 \mathrm{mg} \cdot \mathrm{dm}^{-3}\right), \mathrm{K}\left(930 \mathrm{mg} \cdot \mathrm{dm}^{-3}\right), \mathrm{Ca}(19,5$ Cmol.dm $\left.{ }^{-3}\right), \operatorname{Mg}\left(5,3 \mathrm{Cmol}_{\mathrm{dm}}{ }^{-3}\right), \mathrm{Al}\left(0,25 \mathrm{Cmol}^{-\mathrm{dm}^{-3}}\right), \mathrm{Na}(0,32$

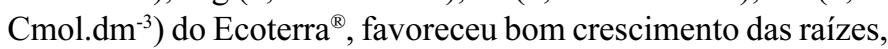
com o sistema radicial bastante ramificado (Fig. 4A), parte aérea com a emissão de novas folhas e expansão das existentes (Fig. 4 B), e altura das plantas (Tabela 6). 
TABELA 1- Resumo da análise de variância para número médio de raízes adventícias (NRA) e comprimento médio da maior raiz (CMR), de jenipapeiro, aos 60 dias de cultivo. Cruz das Almas - BA, 2006.

\begin{tabular}{lccc}
\hline & & \multicolumn{2}{c}{ Quadrados médios } \\
\cline { 3 - 4 } Fonte de Variação & GL & NRA $^{1}$ & CMR $^{2}$ \\
\hline AIB & 3 & $21,2575 * *$ & $0,4552 * *$ \\
BAP & 4 & $2,2331 \mathrm{~ns}$ & $0,0415 \mathrm{~ns}$ \\
AIB x BAP & 12 & $2,1208 *$ & $0,0326 \mathrm{~ns}$ \\
Genótipo & 1 & $23,2146 * *$ & $0,5781 * *$ \\
AIB x Genótipo & 3 & $3,3189 *$ & $0,0903 * *$ \\
BAP x Genótipo & 4 & $4,4873 * *$ & $0,0626 *$ \\
AIB x BAP x Genótipo & 12 & $1,3252 \mathrm{~ns}$ & $0,0264 \mathrm{~ns}$ \\
Resíduo & 200 & 1,1408 & 0,0229 \\
\hline CV (\%) & & 66,9044 & 6,2155 \\
\hline
\end{tabular}

"e* significativo a 1 e $5 \%$ de probabilidade, respectivamente, pelo teste de

${ }^{1}$ transformado para raiz $(\mathrm{x}+0,5) .^{2}$ transformado para $\log (\mathrm{x}+10)$.

TABELA 3- Porcentagem de enraizamento in vitro, em relação ao efeito residual do BAP, em dois genótipos de jenipapeiro, aos 60 dias de cultivo. Cruz das Almas $-\mathrm{BA}, 2006$.

\begin{tabular}{|c|c|c|c|c|}
\hline \multirow{3}{*}{$\begin{array}{l}\text { Genótipo } \\
\text { JRB }\end{array}$} & \multicolumn{3}{|c|}{ AIB } & \multirow[b]{2}{*}{$14,7 \mu \mathrm{M}$} \\
\hline & $\mathbf{0 , 0} \boldsymbol{\mu M}$ & $4,9 \mu M$ & $9,8 \mu M$ & \\
\hline & \multicolumn{3}{|c|}{$\%$ de enraizamento } & \\
\hline \multicolumn{5}{|c|}{$0,0 \mu M$ BAP } \\
\hline $\begin{array}{l}59 \\
69\end{array}$ & $\begin{array}{l}0,0 \\
0,0\end{array}$ & $\begin{array}{c}50 \\
83,33\end{array}$ & $\begin{array}{c}66,66 \\
100\end{array}$ & $\begin{array}{c}16,66 \\
50\end{array}$ \\
\hline \multicolumn{5}{|c|}{$2,22 \mu M$ BAP } \\
\hline $\begin{array}{l}59 \\
69\end{array}$ & $\begin{array}{l}0,0 \\
0,0\end{array}$ & $\begin{array}{l}66,66 \\
66,66 \\
\end{array}$ & $\begin{array}{l}83,33 \\
66,66 \\
\end{array}$ & $\begin{array}{l}33,33 \\
33,33 \\
\end{array}$ \\
\hline \multicolumn{5}{|c|}{$\mathbf{8 , 8 7} \mu \mathrm{M}$ BAP } \\
\hline $\begin{array}{l}59 \\
69\end{array}$ & $\begin{array}{l}0,0 \\
0,0\end{array}$ & $\begin{array}{c}50 \\
66,66\end{array}$ & $\begin{array}{l}0,0 \\
50\end{array}$ & $\begin{array}{l}0,0 \\
50\end{array}$ \\
\hline \multicolumn{5}{|c|}{ 17,74 $\mu$ M BAP } \\
\hline $\begin{array}{l}59 \\
69\end{array}$ & $\begin{array}{l}0,0 \\
0,0\end{array}$ & $\begin{array}{l}0,0 \\
50\end{array}$ & $\begin{array}{l}33,33 \\
83,33\end{array}$ & $\begin{array}{l}33,33 \\
66,66\end{array}$ \\
\hline \multicolumn{5}{|c|}{$26,63 \mu M$ ВАP } \\
\hline $\begin{array}{l}59 \\
69\end{array}$ & $\begin{array}{l}0,0 \\
0,0\end{array}$ & $\begin{array}{c}0,0 \\
66,66\end{array}$ & $\begin{array}{c}83,33 \\
50\end{array}$ & $\begin{array}{l}16,66 \\
66,66\end{array}$ \\
\hline
\end{tabular}

TABELA 5- Porcentagem de sobrevivência de plantas micropropagadas em relação aos estádios de aclimatização, em dois genótipos de jenipapeiro. Cruz das Almas - BA, 2006.

\begin{tabular}{lcc}
\hline & \multicolumn{2}{c}{ \% de sobrevivência } \\
\cline { 2 - 3 } Estádio de aclimatização & Genótipo & Genótipo \\
& JRB 59 & JRB 69 \\
\hline $\begin{array}{l}\text { Após 5 dias em bandeja coberta com plástico } \\
\text { transparente, na sala de crescimento }\end{array}$ & 100 & 100 \\
$\begin{array}{l}\text { Após 10 dias em sala à temperatura ambiente, } \\
\text { em bandeja coberta com plástico transparente }\end{array}$ & 60 & 90 \\
$\begin{array}{l}\text { Após 15 dias em bandeja totalmente } \\
\text { descobertas, em sala à temperatura ambiente }\end{array}$ & 30 & 70 \\
\hline
\end{tabular}

TABELA 2 - Número médio de raízes e comprimento médio de raízes, em relação ao efeito residual do $\mathrm{BAP}$, em dois genótipos de jenipapeiro, aos 60 dias de cultivo. Cruz das Almas - BA, 2006.

\begin{tabular}{lccccc}
\hline \multirow{2}{*}{ Genótipo } & $\mathbf{5 , 0 0}$ & $\mathbf{2 , 2 2}$ & $\mathbf{8 , 8 7}$ & $\mathbf{1 7 , 7 4}$ & $\mathbf{2 6 , 6 3}$ \\
\hline \multicolumn{5}{c}{ Número médio de raízes } \\
\hline JRB59 & $2,79 \mathrm{a}$ & $3,38 \mathrm{a}$ & $0,46 \mathrm{~b}$ & $1,96 \mathrm{~b}$ & $1,08 \mathrm{~b}$ \\
JRB69 & $1,54 \mathrm{a}$ & $5,50 \mathrm{a}$ & $4,83 \mathrm{a}$ & $8,71 \mathrm{a}$ & $6,63 \mathrm{a}$ \\
\hline \multicolumn{5}{c}{ Comprimento médio de raízes } \\
\hline JRB59 & $1,33 \mathrm{a}$ & $1,52 \mathrm{~b}$ & $0,29 \mathrm{~b}$ & $0,63 \mathrm{~b}$ & $0,79 \mathrm{~b}$ \\
JRB69 & $1,10 \mathrm{a}$ & $2,73 \mathrm{a}$ & $2,05 \mathrm{a}$ & $2,69 \mathrm{a}$ & $2,75 \mathrm{a}$ \\
\hline \multicolumn{7}{c}{ Médias seguidas de mesma letra, minúscula na linha, não diferem entre si, }
\end{tabular}

pelo teste de Tukey, a $5 \%$ de probabilidade.

TABELA 4 - Porcentagem de enraizamento por brotação em função da concentração de AIB, em genótipos de jenipapeiro. Cruz das Almas - BA, 2006.

\begin{tabular}{ccc} 
AIB ( M) & \multicolumn{2}{c}{ Enraizamento (\%) } \\
\hline 0,0 & JRB 59 & JRB 69 \\
$\mathbf{4 , 9}$ & 0,0 & 0,0 \\
$\mathbf{9 , 8}$ & 23,4 & 66,7 \\
$\mathbf{1 4 , 7}$ & 43,3 & 70 \\
\hline
\end{tabular}

TABELA 6 - Porcentagem de sobrevivência, e altura das plantas em dois genótipos de jenipapeiro, aos 30 dias de aclimatização, sob efeito de três substratos. Cruz das Almas - BA, 2006. Sobrevivência Altura das plantas

\begin{tabular}{lcccc}
\multirow{2}{*}{ Substrato } & \multicolumn{2}{c}{$\begin{array}{c}\text { Sobrevivência } \\
\text { (\%) }\end{array}$} & \multicolumn{2}{c}{$\begin{array}{c}\text { Altura das plantas } \\
(\mathbf{c m})\end{array}$} \\
\cline { 2 - 5 } & JRB 59 & JRB 69 & JRB 59 & JRB 69 \\
\hline Ecoterra $\left.^{(}\right)$ & $30 \mathrm{aA}$ & $50 \mathrm{aA}$ & $2,19 \mathrm{aA}$ & $2,46 \mathrm{aA}$ \\
Plantmax $^{\circledR}$ HT & - & - & - & - \\
Areia lavada & $10 \mathrm{aA}$ & $20 \mathrm{aA}$ & $2,04 \mathrm{bB}$ & $2,07 \mathrm{bA}$
\end{tabular}

Médias seguidas de mesma letra, minúscula na coluna e maiúscula na linha, não diferem entre si, pelo teste de Tukey, a $5 \%$ de probabilidade.
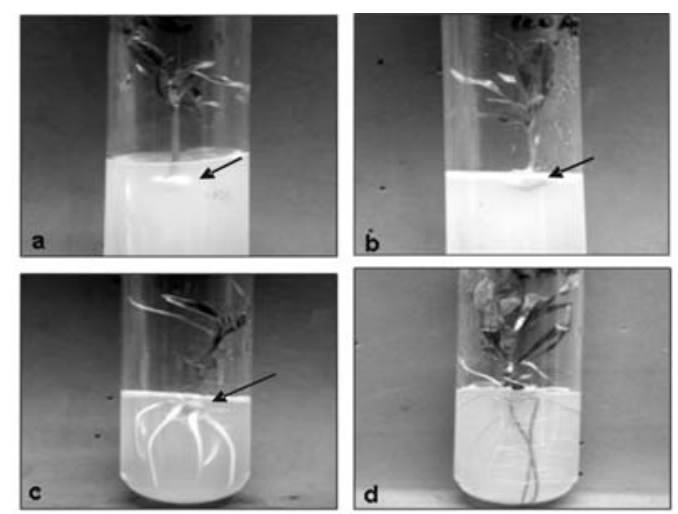

FIGURA 1- Brotações de jenipapeiro aos 60 dias de cultivo em meio de enraizamento com AIB. Calos formados na base das brotações dos genótipos JRB59 (a) e JRB69 (b); Calo na base da brotação com emissão de raízes (c) e enraizamento sem formação de calos (d). Cruz das Almas - BA, 2006. 


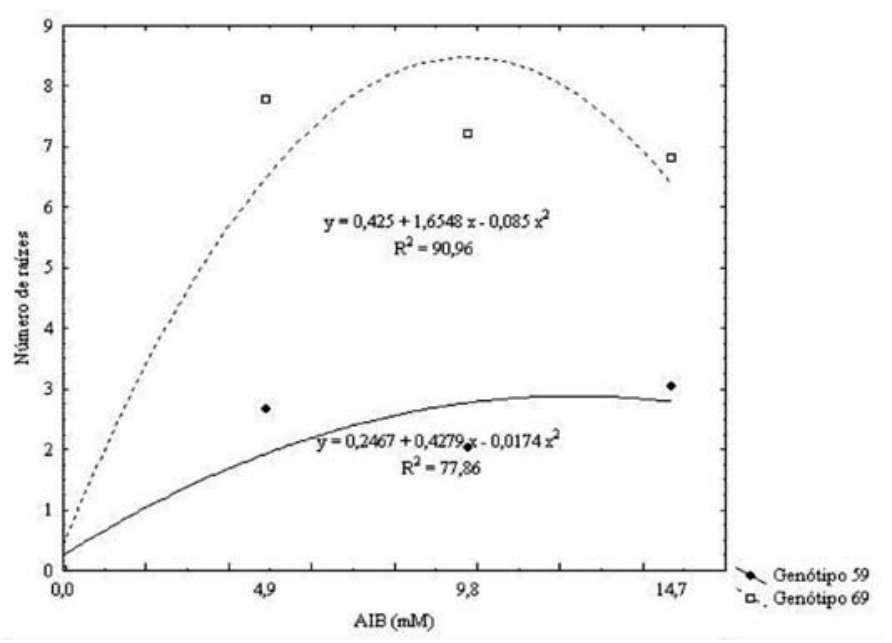

FIGURA 2 - Efeito do AIB no número médio de raízes adventícias, em genótipos de jenipapeiro, aos 60 dias de cultivo. Cruz das Almas - BA, 2006.

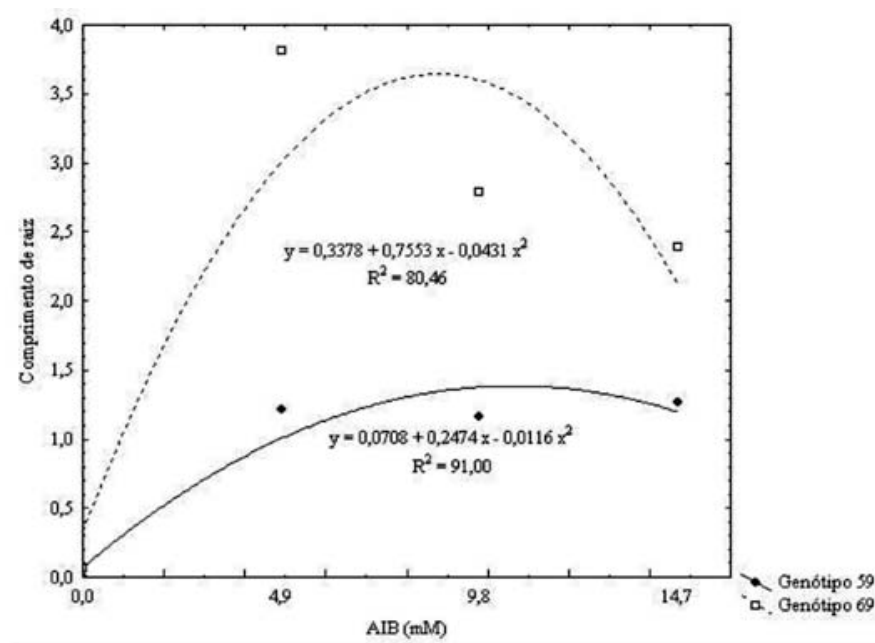

FIGURA3 - Efeito do AIB no comprimento da maior raiz (cm), em genótipos de jenipapeiro, aos 60 duas de cultivo. Cruz das Almas - BA, 2006.

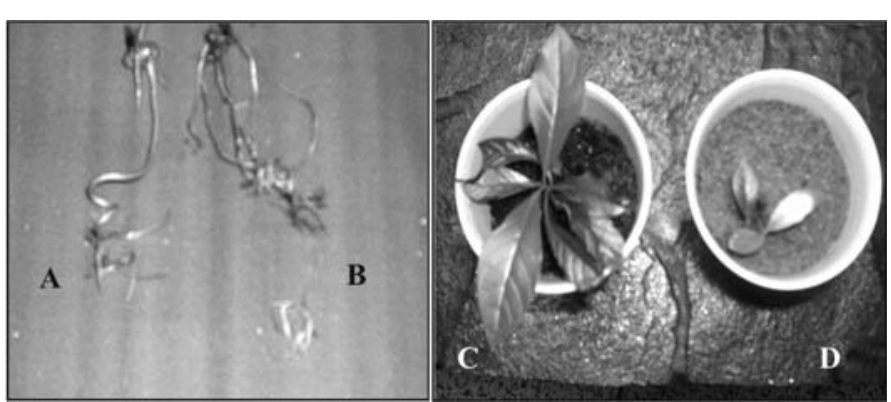

FIGURA 4- Aspecto do desenvolvimento do sistema radicial de plantas de jenipapeiro aclimatizadas em areia lavada (A) e Ecoterra $^{\circledR}$ (B); da parte aérea em Ecoterra $^{\circledR}$ (C) e areia lavada (D), independentemente do genótipo. Cruz das almas $-\mathrm{BA}, 2006$.

\section{CONCLUSÕES}

1-O AIB é indispensável no meio de enraizamento de brotações de jenipapeiro.

2-A concentração de $9,8 \mu \mathrm{M}$ de AIB proporciona maior percentagem de enraizamento, independentemente do genótipo.

3-O genótipo JRB69 é mais responsivo in vitro, quanto ao número de raízes adventícias e comprimento das raízes comparado ao genótipo JRB59.

4-Os substratos areia lavada e Ecoterra ${ }^{\circledR}$ influenciam de forma significativa na aclimatização de plantas de jenipapeiro.

5-O substrato Ecoterra ${ }^{\circledR}$ influencia de maneira positiva na altura, arquitetura do sistema radicial e qualidade da parte aérea das plantas aclimatizadas, independentemente do genótipo.

\section{REFERÊNCIAS}

BEBENDO, I.P. Podridões de raiz e colo. In: BERGAMIN FILHO, A.; KIMATI, H.; AMORIM, L. (Ed.). Manual de fitopatologia: princípios e conceitos. 3.ed. São Paulo: Agronômica Ceres, 1995. v.1, p.829-837.

CALVETE, E.O.; KÄMPF, A.N.; DAUDT, R. Efeito do substrato na aclimatização ex vitro de morangueiro cv Campinas, Fragaria $x$ ananassa Duch. In: KÄMPF, A.N.; FERMINO, M.H. (Ed.). Substrato para plantas: a base da produção vegetal em recipientes. Porto Alegre: Genesis, 2000. p.257-264.

DÍAZ-PÉREZ, J.C.; SUTTER; E.G.; SHACKEL, K.A. Acclimatization and subsequent gas-exchange, water relations, survival and growth of microcultured apple plantlets after transplanting them in soil. Physiologia Plantarum, Copenhagen, v. 95, p. 225-232, 1995.

ERIG, A. C.; SCHUCH, M. W. In vitro rooting of quince cv. MC as rootstock for pear and acclimatization of the rooted microcuttings. Ciência Rural, Santa Maria, v. 34, n.5, p.1443$1449,2004$.

ERIG, A. C.; SCHUCH, M. W.; CHAVES, A. C. Enraizamento in vitro e aclimatização de mudas de marmeleiro Cvs. Mc e Adams, utilizadas como porta-enxerto para a pereira. Scientia Agraria, Curitiba, v. 5, n.1-2, p.61-68, 2004.

FERREIRA, D. F. Análises estatísticas por meio do SISVAR para Windows versão 4.0. In: Reunião ANUAL DA REGIÃO BRASILEIRA DA SOCIEDADE INTERNACIONAL DE BIOMETRIA, 45., São Carlos. Resumos expandidos... São Carlos :UFSCAR, 2000. p. 255-258.

GRATTAPAGLIA, D.; MACHADO, M. A. Micropropagação. In: TORRES, A. C.; CALDAS, L.S.; BUSO, J. A. Cultura de tecidos e transformação genética de plantas. Brasília: Embrapa-SPI / Embrapa-CNPH, 1998. p.183-260. 
LOPES, S. C.; LAMEIRA, O. A.; FORTES, G. R. L.; NOGUEIRA, R. C.; PINTO J.E. B. P. Enraizamento in vitro de mogno (Swietenia macrophylla King). Cerne, Lavras, v.7, n.1, p.124-128, 2001.

MACHADO, M. P.; MAYER, J. L. S.; RITTER, M. et al. Indole butyric acid on rooting ability of semihardwood cutting of grapevine rootstock 'VR 043-43' (Vitis vinifera $\mathrm{x}$ Vitis rotundifolia). Revista Brasileira de Fruticultura, Jaboticabal, v. 27, n. 3, p. 476-479, 2005.

MAGALHÃES JUNIOR, A. M.; PETERS, J.A. Cultura in vitro de ameixeira: Efeito do ácido indolbutírico, tipo de lâmpada e intensidade luminosa no enraizamento. Revista Brasileira de Fisiologia Vegetal, Londrina, v.3, n.1, p.57-61, 1991.

MURASHIGE, T.; SKOOG, F. A revised medium for rapid growth and bio assays with tobacco tissue cultures. Physiologia Plantarum, Lund, v. 15, p. 473 497, 1962.

RADMANN, E.B.; FACHINELLO, J.C.; PETERS, J.A. Efeito de auxinas e condições de cultivo no enraizamento in vitro de portaenxerto de macieira 'M-9'. Revista Brasileira de Fruticultura, Jaboticabal, v.24, n.3, p.624-628, 2002.

SANTANA, J. R. F. Controle da morfogênese in vitro em algumas espécies de Annonaceae. 2003. 237 f. Tese (Doutorado em Agronomia - Fisiologia Vegetal) - Universidade Federal de Lavras, Lavras, 2003.

SAS INSTITUTE INC. SAS/STAT User's Guide. v. 8.0. Cary, NC, 2000. v.1.
SOBROSA, R. C.; CORDER, M. P. M. Efeito do genótipo sobre o potencial para produção de gemas e raízes adventícias em Eucalyptus grandis Hill ex Maiden in vitro. Floresta e Ambiente, Seropédica, v. 10, n.1, p.58-68, 2003.

SOUZA, F. V. D. ; COSTA, M. A. P. C. ; SILVA NETO, PEREIRA, H. Aclimatização. In: SOUZA, A. da S.; JUNHANS, T. G.. (Org.). Introdução a micropropagação de plantas. Cruz das Almas: EMBRAPA Mandioca e Fruticultura Tropical, 2006. v. 1, p. 131140.

SUTTER, E. Stomatal and cuticular water loss from apple, cherry and sweetgum plants after removal from in vitro culture. Journal of American Society for Horticultural Science, Washington, v.113, n.2, p.234-238, 1988.

TRICOLI, D.W.; MAYMNARD, C.A.; DREW, A.P. Tissue culture of propagation of mature trees of Prunus serotina Enrh. I. establishment, multiplication, and rooting "in vitro". Forest Science, New Brunswick, v. 31, n.1, p. 201-208, 1985.

VANTELGEN, H.J.; VANMIL, A.; KUNNEMAN, B. Effect of propagation and rooting condition on acclimatization of micropropagated plants. Acta Botanica Neerlandica, Amsterdan, v.41, n.4, p.453-459, 1992.

WELANDER, M.; SNYGG, O. Effect of applied and endogenous auxin on callus and root formation of in vitro shoots of the apple rootstocks M26 and A2 . Annals of Botany, London, v. 59, n. 4, p. 439-443, 1987.

WILLIAMS, R.R.; TAJI, A.M.; BOLTON, J.A. Specificity and interation among auxin, light, and $\mathrm{pH}$ in rooting of Australian woody species in vitro. Hortscience, St. Joseph, v. 20, n.6, p. 1052-1053, 1985. 